\title{
Anabases
}

ANABASES Traditions et réceptions de l'Antiquité

$9 \mid 2009$

Varia

\section{Perrine GALAND-HALLYN, Carlos LÉVY (dir.), La villa et l'univers familial dans l'Antiquité et à la Renaissance}

\author{
Laure Hermand-Schebat
}

\section{(2) OpenEdition}

Journals

Édition électronique

URL : http://journals.openedition.org/anabases/569

DOI : 10.4000/anabases.569

ISSN : 2256-9421

Éditeur

E.R.A.S.M.E.

Édition imprimée

Date de publication : 1 mars 2009

Pagination : 328-329

ISSN : 1774-4296

Référence électronique

Laure Hermand-Schebat, "Perrine GALAND-HALLyN, Carlos LÉvy (dir.), La villa et l'univers familial dans l'Antiquité et à la Renaissance », Anabases [En ligne], 9 | 2009, mis en ligne le 01 juillet 2011, consulté le 22 septembre 2020. URL : http://journals.openedition.org/anabases/569 ; DOI : https://doi.org/ 10.4000 /anabases.569

Ce document a été généré automatiquement le 22 septembre 2020

(c) Anabases 


\title{
Perrine GALAND-HALLYN, Carlos LÉVY (dir.), La villa et l'univers familial dans l'Antiquité et à la Renaissance
}

\author{
Laure Hermand-Schebat
}

\section{RÉFÉRENCE}

Perrine GALAND-HALlyn, Carlos lÉvy (dir.), La villa et l'univers familial dans l'Antiquité et à la Renaissance, Paris, PUPS, 2008, 292 p.

25 euros / ISBN : 978-2-84050-538-9.

1 Cet ouvrage collectif approfondit la réflexion sur l'individu et la sphère privée dans l'Antiquité et à la Renaissance, amorcée par le premier volume de la collection « Rome et ses renaissances » intitulé Vivre pour soi, vivre pour la cité, de l'Antiquité à la Renaissance, paru en 2006.

Il propose dans une première partie six contributions consacrées à l'espace de la villa, lieu qui permet l'élaboration d'une image du moi privé, libéré de ses obligations publiques. Sylvie Agache montre comment à Rome la villa, lieu de l'otium depuis Scipion l'Africain, représente l'homme. Les auteurs de la fin de la république que sont Cicéron et Varron justifient le luxe de leurs villas, le premier par la notion de dignitas, le second par l'identification de la beauté et de l'utilité. Alain Deremetz s'intéresse aux descriptions de villas chez les poètes Horace et Martial. L'art de vivre lié à la villa est toujours aussi un art d'écrire: éthique et poétique du juste milieu chez le poète de Venouse ou projet éthique et poétique de l'intertextualité chez l'épigrammatiste. Stéphanie Wyler étudie le dionysisme, culte privé, à partir de la décoration des villas que sont la maison du Faune à Pompéi et la villa de la Farnésine à Rome. La décoration de cette dernière, dans l'association de Bacchus et de Vénus, transmet un message dynastique propre à la politique augustéenne. À la Renaissance, les humanistes reprennent à leur compte ce motif de la villa comme élément décisif pour exprimer 
l'individualité et l'intimité. Ginette Vagenheim rétablit le rôle essentiel joué par l'antiquaire du XvI ${ }^{e}$ siècle Pirro Ligorio dans les premières études architecturales de la villa d'Hadrien à Tivoli, qui ont d'ailleurs fortement influencé la conception de la villa d'Este. Anne Bouscharain analyse un choix de poèmes et une lettre de Battista Spagnoli, poète mantouan du Quattrocento qui revivifie la tradition antique en liant peinture de la villa et recherche d'un otium érudit : la villa devient le lieu par excellence de la création poétique. Sa silve consacrée à la villa de son ami Refrigerio est un éloge improvisé à la manière de Stace, «hommage vibrant et non conventionnel à l'amitié et aux lettres » (p. 116). Enfin, Perrine Galand-Hallyn prend en considération les descriptions de villas chez les humanistes du $\mathrm{xvI}^{\mathrm{e}}$ siècle. La villa est d'abord chez ces auteurs le lieu privilégié pour dire l'intimité ; les descriptions humanistes de la villa donnent lieu à un portrait ou à un autoportrait. Lieu de l'otium méditatif chez Michel de L'Hospital, la villa habite l'otium amoureux de Jean Salmon Macrin et de sa future épouse; chez Germain de Brie, la villa est liée à la pratique de l'amitié. Mais chez L'Hospital et Crinito, la villa n'est pas sans rapport non plus avec le negotium lui-même: le premier met en valeur l'utilité politique du repos campagnard tandis que le second fait du jardin et de la villa des Rucellai un symbole de résistance politique dans la Florence de la fin du Quattrocento.

3 La seconde partie, en continuité avec la première, met en rapport l'univers familial à Rome sous l'empire et en Europe à la Renaissance. Les trois premières contributions éclairent par des approches différentes la conception nouvelle du mariage sous l'Empire. Valéry Laurand, choisissant le philosophe stoïcien Musonius Rufus, contemporain de Néron, note « la coïncidence apparente de l'idéologie d'Auguste sur le mariage, la famille et la nation et les développements du philosophe sur les mêmes sujets» (p.148). Mais chez Musonius, le mariage n'est pas uniquement lié à la procréation; la communauté des époux en constitue la fin (telos) alors que la procréation n'en est que le but (skopos). Valéry Laurand montre l'originalité de l'harmonie musonienne du couple dans lequel les époux sont égaux devant la vertu. Virginie Leroux commente le réseau lexical du joug comme image du lien conjugal dans les tragédies de Sénèque. Elle s'interroge ensuite sur «l'éthique du comportement conjugal» (p.181) dans les tragédies et les traités en prose, dont les fragments du De matrimonio. La fureur des viduae dans les tragédies fait écho à la condamnation du célibat et à une position en faveur du mariage et du remariage. Sylvie Franchet d'Esperey s'intéresse à la Thébaïde de Stace : la vision positive des personnages féminins rapproche l'épopée de la silve. Le principe conjugal développé par Stace dans son épopée vient enrichir la notion épique de pietas; sans faire voler en éclats le cadre épique, la poétique de Stace l'infléchit considérablement. John Nassichuk commente une élégie de l'humaniste napolitain Giovanni Pontano dans laquelle la villa réunit le motif pastoral et l'éloge de la vie conjugale; il analyse le travail de "contaminatio inventive » (p. 206) qui s'y fait jour. Aline Semeesters compare les Naeniae, berceuses écrites par Pontano pour son fils Lucio, et quelques traités pédagogiques contemporains du poète : elle concentre son analyse sur le discours que tiennent les adultes devant les nourrissons. Émilie Séris s'intéresse à la défense de l'allaitement maternel, à ses fondements et à ses implications dans la Paidotrophia de Scévole de Sainte Marthe (1584).

4 Le volume fournit en outre une bibliographie riche et variée, ainsi qu'un index très complet qui inclut personnes antiques et renaissantes, titres d'œuvres et critiques contemporains. La perspective diachronique choisie par les auteurs se révèle 
extrêmement féconde, faisant apparaître points de continuité et points de rupture entre l'Antiquité et la Renaissance. Outre la qualité des articles, la diversité des domaines couverts (poétique, philosophie, histoire de l'art, histoire des idées) rend cet ouvrage utile à un large public.

\section{AUTEURS}

\section{LAURE HERMAND-SCHEBAT}

PRES Lyon-Université, Lyon 3-Jean Moulin

hermand@univ-lyon3.fr 